\title{
Brinquedos e brincar na vida de mulheres educadoras negras
}

\author{
Marilda Castelar \\ Escola Bahiana de Medicina e Saúde Pública - Salvador - BA \\ Flávia Cristina Silveira Lemos \\ Universidade Federal do Pará - Belém - PA \\ Jamille Georges Reis Khouri \\ Escola Bahiana de Medicina e Saúde Pública - Salvador - BA \\ Thaís Andrade \\ Escola Bahiana de Medicina e Saúde Pública - Salvador - BA
}

\section{Resumo}

Este artigo aborda o brincar e o brinquedo na constituição da mulher negra pelas práticas educativas escolares, no ensino básico, público e privado. As práticas escolares devem interrogar a produção e reprodução dos padrões comportamentais e estéticos, os quais operam relações de discriminação negativa de gênero e raciais. Na pesquisa foram utilizados como recursos metodológicos: a história oral, por meio de histórias de vida e entrevistas gravadas e transcritas com oito mulheres, professoras negras, em Salvador (BA). Foi realizado levantamento bibliográfico e revisão da literatura. As análises foram feitas pela análise de conteúdo, a partir das seguintes categorias: memórias, relações com a atualidade e as práticas profissionais ligadas à gênero e racismo na escola. O brinquedo e a brincadeira apareceram como analisadores do racismo e estereótipo de gênero na educação escolar, implicando no sofrimento das crianças. Sugere-se a adaptação curricular no trabalho escolar, considerando a promoção da equidade escolar.

Palavras-chave: Raça; crianças; brinquedos.

\section{Toys and play in the lives of black women educators}

\begin{abstract}
This article discusses the play and the toy in the constitution of black women by school education practices, basic education, public and private. School practices should examine the production and reproduction of behavioral and aesthetic standards, which operate negative discrimination of gender relations and racial. In the survey were used as methodological resources: the oral history through life stories and recorded and transcribed interviews with eight women, African teachers in Salvador (BA). It was conducted literature and literature review. Analyses were performed by the content analysis, from the following categories: memories, relationships with current and professional practices related to gender and racism at school. The toy and the game appeared as racism analyzers and gender stereotypes in education, resulting in the suffering of children. Curriculum adaptation is suggested in schoolwork, considering the promotion of educational equity.
\end{abstract}

Keywords: Race; children; toys.

\section{Juguetes y jugar en la vida de mujeres educadoras negras}

\section{Resumen}

Este artículo aborda el jugar y el juguete en la constitución de la mujer negra por las prácticas educativas escolares, en la enseñanza básica, público y privado. Las prácticas escolares deben interrogar la producción y reproducción de los patrones comportamentales y estéticos, los cuales operan relaciones de discriminación negativa de género y raciales. En la investigación se utilizaron como recursos metodológicos: la historia oral, por medio de historias de vida y entrevistas grabadas y transcritas con ocho mujeres, profesoras negras, en Salvador (BA). Se realizó el levantamiento bibliográfico y revisión de la literatura. Los análisis fueron hechos por el análisis de contenido, a partir de las siguientes categorías: memorias, relaciones con la actualidad y las prácticas profiseonales ligadas al género y racismo en la escuela. El juguete y el juego aparecieron como analizadores del racismo y estereotipo de género en la educación escolar, implicando en el sufrimiento de los niños. Se sugiere la adaptación curricular en la labor escolar, considerando la promoción de la equidad escolar.

Palabras clave: Raza; niños; juguetes. 


\section{Introdução}

O presente artigo fez parte de projeto de pesquisa sobre direitos, ética e relações raciais no campo de estudos sobre memória, cultura e subjetividade. Pensar a criança por meio da brincadeira, dos brinquedos e dos processos de produção de modelos de ser, de sentir e de pensar marcados por gênero e racismo é uma contribuição relevante no que tange à criação de um currículo baseado na valorização da diferença.

As crianças negras, no Brasil, sofrem, ainda, com a produção e reprodução de um modelo eurocêntrico, enraizado a partir do processo histórico de escravidão e suas atualizações. A naturalização da branquitude leva as crianças a desvalorizarem a negritude. Os brinquedos são artefatos culturais que materializam práticas divisórias, relações de poder e de saber, forjam assujeitamentos por meio da socialização de crianças baseada em valores socioculturais presentes na sociedade.

Os brinquedos e as brincadeiras fazem parte do processo de educação e socialização da criança, e podem funcionar como moduladores da construção de processos de assujeitamentos, pautados em estereótipos. Contudo, podem também ser operadores de engendramentos de processos de singularização, em meio às possibilidades educativas e às ordens discursivas que ocorrem em nossa sociedade.

Assim, a escola e os educadores poderão fomentar o respeito à singularização e romper com qualquer tipo de discriminação negativa, como a racial e a de gênero. Mas será que nossas escolas assumem essa responsabilidade ou reproduzem o embranquecimento encontrado na sociedade? Com o surgimento da lei 10.639/03 (Lei $n^{\circ} 10.639,2003$ ) torna-se obrigação das escolas fornecer o ensino da história e cultura afro-brasileira e africana, mas será que esta Lei está sendo concretizada? E de que forma esse assunto é tratado?

Este texto se debruça sobre essas questões e, para tentar respondê-las, contou com o relato e reflexões de mulheres negras, envolvidas no processo de educação de crianças, na atualidade, a partir de pesquisa na área de saúde coletiva, qualitativa, realizada com entrevistas às muIheres negras educadoras, em Salvador/BA.

\section{Construção da subjetividade marcada pela negritude na infância}

A produção de subjetividades no campo histórico e social é um movimento contínuo indissociável da sociedade (Ciampa, 1994). Essa ideia se relaciona com os argumentos de Ferreira e Camargo (2011), ao afirmarem que nos referenciamos em crenças, códigos e valores enraizados historicamente para nos constituirmos. Com efeito, a negritude como possibilidade, ainda hoje, é construída em torno de valores considerados socialmente negativos devido ao processo social e histórico de construção do nosso país, mar- cado pela escravidão de pessoas de pele negra, relacionada à ideia de superioridade racial do branco-europeu (Ferreira, \& Camargo, 2011).

No contexto social brasileiro, em que o ideal de ser branco é extremamente positivado, modulações de vida baseadas em legados africanos são desvalorizadas (Ferreira,\& Camargo, 2011). É comum, portanto, que o afrodescendente se observe a partir de um campo de normas: do "branco ser certo" e do "negro ser errado" (Ferreira, 2000).

Como afirmam Souza, Lopes e Santos (2007), desde criança o negro é marcado por estereótipos depreciativos, em uma intensa produção de uma imagem negativa de si mesmo. Segundo o Referencial Curricular para a Educação Infantil - Vol. 2 (Brasil, 1998), a construção da criança ocorreria de forma gradativa, através das interações sociais estabelecidas por ela, em que o modo como uma criança é vista pelo outro também interfere em como ela própria se vê.

Para problematizar a construção de trajetórias da criança negra, é igualmente fundamental considerar as situações de racismo e discriminação vivenciadas por ela. As crianças negras comumente são alvo de preconceitos nos equipamentos de educação infantil. As práticas de negação e desqualificação racistas ocorrem com frequência por parte dos profissionais de educação, dos colegas e até da própria família. Diante disso, elas têm o seu processo de aprendizagem e socialização comprometidos por estigmas variados, que as fazem sofrer desde cedo (Santana, 2006).

É possível perceber, no interior das creches, a busca por um ideal de belo transmitido para as crianças, a partir de estereótipos e brinquedos e brincadeiras (Costa de Souza, 2010). Um exemplo disso é o conflito vivenciado principalmente pela menina negra em relação ao seu cabelo crespo, seu nariz largo e sua pele escura, devido à incorporação de um padrão estético (Souza, Lopes, \& Santos, 2007).

Em face do que se ressaltou, torna-se importante citar o processo de branqueamento e seus efeitos. Segundo Bento (2012), esse processo foi criado por grupos diversos no Brasil, durante a colonização,e se mantém ao longo de séculos. Obviamente, há variações e atualização do racismo, porém, ele se materializa concretamente por meio de normas, instituições e nas leis. Relações de poder e saber se misturam com um campo de dominação social e econômica ainda bastante difuso, nas relações sociais. A mulher negra, portanto, ao fazer parte de dois grupos desvalorizados, historicamente, tem sua vida marcada por preconceitos presentes na sociedade.

\section{O brinquedo e as relações de poder e saber}

Na infância, o brinquedo assume o lugar de um importante modulador na construção da subjetividade. Para Brougère (2010), o brinquedo é um objeto, o qual fornece valores e normas, mediadores históricos e culturais da brincadeira. Através dele, a criança entra em contato com um discurso cultural sobre a sociedade, o que lhe permite atuar com base em códigos sociais. O brinquedo é um dos meios 
e suportes para a brincadeira, abrindo possibilidades dialógicas e polissêmicas. Pode ser um objeto manufaturado, uma sucata, um objeto adaptado, ou seja, tudo pode se tornar um brinquedo, a partir de como quem brinca atua com esse objeto.

Com efeito, os brinquedos explicitam valores e ideais (Cruz, 2012). Por essa perspectiva, podemos analisar porque é comum as crianças brincarem com bonecos e bonecas que seguem um padrão estético de pele branca, olhos azuis e cabelos loiros (Dornelles, 2003). As marcas das relações de poder existentes na sociedade são atravessadas pelos brinquedos e neles materializadas, nos fornecendo padrões e ideais de beleza, de corpo e de sujeito (Cruz, 2012), reforçados constantemente pela mídia, que apresenta os brinquedos, direciona culturas e relações sem determiná-las em lógicas causais.

A variedade de brinquedos, apresentando expressões das diferenças raciais, de gênero, geração ou étnicas ainda é rara e de difícil acesso. Esse fato pode levar a criança a construir um modelo de normalidade, no qual as diferenças passam a ser desconsideradas (Dornelles, 2003):

Os brinquedos vêm se constituindo como uma forma de governo e auto-governo das crianças. Suas formas produzem efeitos, fabricando modos de subjetivação que aprisionam os infantis a "verdades" sobre como deve ser seu corpo, seu comportamento, suas atitudes, seus valores, (Dornelles, 2003, p.8).

Outro ponto que merece ser discutido sobre os brinquedos é a sua caracterização de gênero. É possível considerar que esse conceito pode desconstruir o determinismo biológico binário (homem e mulher), ao levar em conta o cotidiano das práticas de ser e estar no mundo. O legado social tradicional define posições sociais e institucionais, a partir da constituição biológica de machos e fêmeas, de feminino e masculino (Torrão Filho, 2005). A cultura traça modelos binários, deixando de ter em vista, assim, outras possibilidades.

O brinquedo funciona como uma forma de diferenciação entre o masculino, feminino, entre atividades divididas por gênero e orientação sexual, através da produção e reprodução social de uma repartição de como se tornar homem e mulher, em determinado contexto histórico e cultural. Dessa maneira, cria um suposto universo feminino, ligado ao cuidado do lar, da família e da beleza; e, masculino, associado às atividades que envolvam a força física e a esfera privada (Cruz, Silva, \& Souza, 2012).

Percebemos uma conexão mais ancorada entre brinquedo e formação do gênero quando percebemos que ambos estão imbricados em relações de poder. E justamente pelo brinquedo ser um artefato cultural eivada de relações de poder, que logo se diferencia o masculino e o feminino. (Cruz, Silva \& Souza, 2012, p. 4).

A boneca Barbie é um dos principais exemplos, na atualidade, dado minação de padrões estéticos e compor- tamentais com respeito às meninas. Com filmes, site, jogos, produtos de beleza etc., a marca Barbie está o tempo todo ofertando um conceito de feminilidade. A menina/mulher deve ser magra, de seios fartos, loira, de pele branca, com cabelos lisos e compridos, além de ser sensível, delicada, generosa, possuir bons modos e gostar de comprar, principalmente produtos cor de rosa e com glitter (Roveri, \& Soares, 2011). Vale ressaltar que mesmo os exemplares negros e pardos da boneca mantêm os mesmos padrões estéticos brancos."Barbie foi feita para ser o espelho inquebrável que reflete a 'melhor' decoração possível para corpos humanos, tidos como frágeis e vulgares, os corpos femininos" (Roveri, \& Soares, 2011, p.161).

Diante das situações acima descritas, acerca do preconceito vivenciado pela criança negra e da pouca variedade de brinquedos disponíveis, torna-se importante analisar: como educadores operam, quanto a esse processo? Nossas escolas concretizam que práticas, para lidar com as questões as quais envolvem as relações raciais e de gênero?

\section{Educadores e os brinquedos dispositivos}

O profissional de educação pode fazer circular outros discursos e atravessar currículos, ou seja, maneiras de pensar e forjar práticas educativas, ofertando outras maneiras de viver e até mesmo deslocando as existentes nas relações que estabelece com a criança e o mundo, de sorte que se posicionar contra qualquer forma de discriminação negativa é fundamental em um campo ético, estético e político. Além disso, essa posição crítica contribui para a construção de práticas democráticas e de cidadania para a sociedade como um todo e não só para a criança (Santana, 2006).

Um mesmo objeto usado para afirmar hierarquias e forjar modelos pode ser utilizado para criar resistências e contrapoderes, nos modos em que é apropriado nas práticas educativas. Operar um ensino histórico e desnaturalizador de normas e preconceitos implica pensar a educação como abertura ao novo e não apenas reprodução social e cultural.

É importante que o educador compreenda que a infância é tomada como uma maneira de fabricar crianças, como se estas fossem homogêneas. Porém, elas fogem a esse campo normalizador e insistem em criar outras relações com o mundo, elas resistem aos modelos (Deleuze, 1995). Educadores podem estar abertos a esse processo conectivo e dar passagem a ele, fazendo operar entremeios, os quais rompam com lógicas binárias e práticas de repartição sectaristas e estigmatizantes, na educação de crianças (Reis, 2010; Santana, 2006).

A infância é apenas um modo de ser criança, em uma crianceria que tem múltiplas cores - e é assim que ela deveria ser retratada nas escolas. Os educadores funcionam como ponto de travessia para as crianças a outros territórios de existência, em nossa sociedade, e podem abrir capôs de multiplicidade.

$\mathrm{Na}$ esfera jurídica das práticas educativas, a Lei 10.639/03 (Lei no 10.639, 2003) tem auxiliado nesse proces- 
so? Ela tem gerado transformações nos espaços educativos ou figura como abstração? Ela opera como um balizador das práticas sociais e nelas forja? Enfatiza Costa de Souza: "O emblema eurocêntrico embranquecido é tão forte que, mesmo com a lei, a escola em seus projetos pedagógicos e práticas cotidianas não a utiliza como ferramenta de desconstrução desse espaço segregatório" (2010, p.75). A promulgação da Lei $n^{\circ} 10.639 / 03$ promove alterações na Lei de Diretrizes e Bases da Educação Nacional (Brasil, 1996), e inclui no currículo oficial dos estabelecimentos de ensino básico das redes pública e privada do país a obrigatoriedade do estudo da temática "história e cultura afro-brasileira", uma vez que isto é imprescindível para a eliminação das desigualdades existentes no sistema educacional (Souza, \& Croso, 2007).

A Lei $n^{\circ} .10 .639 / 03$ concebe as escolas como um espaço privilegiado para promover a discussão e analisar as relações raciais, no Brasil. Também prescreve diretrizes de problematização da construção histórica e social das concepções raciais. Além disso, os espaços educativos deveriam pensar, por meio da brincadeira,as práticas preconceituosas e discriminatórias, de forma a questionar as relações que desqualificam negros frente aos brancos, por exemplo. Todavia, qual ressonância tem essa lei,no currículo e nos processos de subjetivação, no cotidiano das práticas escolares?

Barros (2012, p.64), ao discutir sobre ações afirmativas, no Brasil, afirma que "(...) os professores mostram-se despreparados, os livros didáticos que abrangem a história da civilização africana ainda são poucos, e dispomos de uma restrita mostra de livros de literatura infantil com personagens negros protagonistas".

O projeto político-pedagógico da escola deve promover o trabalho em torno de uma discussão crítica quanto às questões raciais e de uma promoção da igualdade de direitos étnico-raciais, porém, isso não é efetivamente feito. A aplicação da lei é analisada através de matérias que contemplem as temáticas étnico-raciais, sem ser preciso considerar que, para a reflexão de tais assuntos, toda a equipe pedagógica, assim como os professores, deve estar empenhada, a fim de que não haja apenas uma mera aplicação superficial de leis. A produção de crítica social e das normas negociadas eticamente e politicamente pode agir nos entremeios, de modo a criar dissidências com modelos hierarquizados de ser (Souza, \& Croso, 2007).

A partir do exposto, é possível refletir como as meninas negras têm suas vidas permeadas por elementos que as aprisionam a determinados modelos estéticos e comportamentais, sendo o brinquedo um destes. Deve-se considerar criticamente, como hipótese, a pouca disponibilidade de brinquedos em que a menina negra possa se pensar e operar diferenciações afirmativas, no âmbito da escolarização brasileira. Nesse sentido, essa pesquisa buscou analisar como os brinquedos são associados a um campo da história de educadoras negras sobre suas vidas e seus efeitos, em sua prática profissional com crianças.

\section{Metodologia}

Paralelamente ao levantamento da literatura, foi realizada uma revisão teórica sobre o tema e a análise de cinco entrevistas piloto com educadoras e psicólogas negras, transcritas. Um segunda rodada de entrevistas foram realizadas com roteiros específicos, mais focados na infância. Assim, foram entrevistadas oito mulheres negras, professoras na educação básica, pública e privada, em Salvador/BA. Uma delas era psicóloga e atuava em escola particular.

Esse processo se deu através da utilização de um roteiro de entrevista semiestruturado, gravações em áudio,durante as entrevistas,esua posterior transcrição. $\mathrm{A}$ entrevista funciona, portanto, como uma forma de produção de sentido, de sorte que "(...) o sentido é uma construção social, um empreendimento coletivo, mais precisamente interativo, por meio do qual as pessoas constroem os termos a partir dos quais compreendem e lidam com as situações e fenômenos a sua volta" (Spink, 2004, p.41).

As análises foram feitas pela análise de conteúdo, baseada em Bardin, iniciada pela leitura flutuante de8 transcrições das entrevistas. Procurou-se, primeiramente, levantar os relatos sobre a história de vida relacionada à infância das entrevistadas e aocontatocom os brinquedos e as brincadeiras nas práticas educativas. Posteriormente, foi investigado o que pensavam sobre as práticas profissionais, às quais desenvolviam como educadoras face à temática do racismo e de gênero.

Nesse processo, emergiramas seguintes categorias de análise: Memórias - foi considerada nessa categoria a descrição dos brinquedos e a percepção das entrevistadas sobre os estímulos produzidos pelos brinquedos durante a sua infância e as consequências para o processo identitário. Relações com a atualidade e suas práticas profissionais -levaram-se em conta os relatos de análise sobre o brinquedo, consumo e mídia, assim como a forma como os brinquedos são fornecidos às crianças. $E$, por último, o racismo na escola - relatado em suas memórias, em suas vivências e práticas profissionais.

\section{Resultados e Discussões}

\section{Memórias}

As histórias de vida analisadas se deram com base na narrativa histórica, baseada na História Oral, nas discussões realizadas sobre a História Nova Cultural, em que o acesso às fontes de grupos excluídos dos arquivos oficiais foi levantado pela produção dos documentos orais, através de entrevistas. Nesse campo, as entrevistadas descreveram os brinquedos da infância, as brincadeiras que marcaram as educadoras e as invisibilidades culturais e sociais das mulheres negras na educação.

As educadoras relataram o uso da invenção e do faz de conta como forma de resistência, e como isso é impor- 
tante para a criança não ser massacrada pelos estereótipos racistas e de gênero. Em acréscimo, as relações entre brinquedo, brincadeira e gênero e brinquedo; brincadeira e raça apareceram associadas, muitas vezes, ao desejo pela boneca loira e às diferenças entre o brinquedo de menino e o de menina como efeito de práticas educativas discriminatórias.

Eu ganhava sempre três tipos de brinquedo que era a xicrinha com o pirezinho e pratinho, o bonecão ou fogãozinho de plástico com quatro panelas (...). Então era isso, e eu assim me lembro muito de que cada vez sonhava, era muito forte o desejo de ter outras coisas, e sonhava com brincar de outras coisas, de ter outros brinquedos, a boneca que falava, que tinha chupeta, que tinha cabelos loiros compridos, isso era fantástico. (Psicóloga, 48 anos).

Então, bom, se eu não podia ter a boneca loira, os fogãozinhos [sic] que eu ganhava pra mim não faziam sentido nenhum. Então, as coisas que eu gostava, que eu fazia, que eu brincava eram coisas do universo masculino, sempre. (Psicóloga, 48 anos).

Me lembro que todos os meninos ganhavam, meus irmãos ganhavam carros, era carro de ambulância, era carro de bombeiro. Meu pai comprava também aqueles carros de madeira, aqueles caminhões (...). E depois quando apareceu aquele carro de bombeiro que apitava, aquelas sirenes de ambulância, era revólver, que hoje em dia a gente não dá mais, né? Mas naquele tempo tinha, tinha metralhadora, meus irmãos tinham aquelas metralhadoras com água, tinha que saía fogo, tudo isso (...). Menino era carro, era isso, menina não. (Pedagoga, 50 anos).

Em relação ao brinquedo e à brincadeira vinculados a gênero, conforme Cruz, Silva e Souza (2012), citados anteriormente foi possível perceber como os brinquedos ofereceram às crianças possibilidades de expressão de sistemas de repartição de gênero, atribuindo às meninas funções de cuidado com o lar, através de fogõezinhos, xicrinhas e da boneca. E, aos meninos, de ação e força física, por intermédio de carro de bombeiro, revólver, metralhadora.

Já, na perspectiva racial, foi interessante perceber como o elemento boneca loira de cabelos compridos apareceu como objeto de desejo da criança. O brinquedo modulou os padrões estéticos e comportamentais da sociedade, o que limitou as possibilidades de subjetivação da criança. A pouca diversidade nos brinquedos direcionou a menina negra a construir verdades e padrões de normalidade fixados em modelos sem mediação educativa.

De acordo com as entrevistadas, pelos brinquedos e brincadeiras há ressonâncias de uma política de branqueamento modeladora de modos de ser. Em contraponto, também foi possível observar como o acesso aos brinquedos com variedade de cores e estilos é interessante para a criança:

Então, quando eu brincava, eu tinha tipo, na época, tinha tipo umas colchas, minha mãe chamava de colcha de chenil.
Eram umas colchas vermelhas, amarelas e tinham umas barrinhas assim que eram umas franjas, eu lembro da gente ter apanhado algumas vezes, porque a gente rasgava a colcha, tirava a franja e amarrava na cabeça, assim, para fazer o cabelo que ficava balançando, então eu lembro isso era muito forte, o desejo de ter o cabelo comprido igual ao das bonecas. (Psicóloga, 48 anos).

Então, eu vou dizer que eu tive boneca de todas as cores, eu tive bonecas com referências variadas e isso eu acredito que me possibilitou olhar para as bonecas de uma forma bem bacana, que é não a mais bonita, não a mais feia, não a mais dessa cor ou daquela, não, olhar para as bonecas. (Entrevistada 3).

No primeiro trecho, é possível perceber indícios do processo de branqueamento nos corpos. Como já citado, com base nos argumentos de Ferreira e Camargo (2011) e Souza, Lopes, e Santos (2007), a menina negra, em busca de um ideal branco, tem dificuldade de aceitar, por exemplo, seus cabelos crespos, o que gera sofrimento. No segundo depoimento destacado, todavia, o acesso às bonecas com diferentes referências se constitui com mais mobilidade de modos de ser na escola.

\section{Relações com a atualidade e suas práticas profissionais}

Devido à inserção no contexto escolar, as entrevistadas produziram uma análise sobre os brinquedos e a maneira como atualmente são difundidos pela mídia, através de propagandas dirigidas às crianças. As consequências são rapidamente colocadas pelo consumismo e pelo sofrimento por quem não pode adquirir esses produtos e nem ainda elaborar o preconceito, a discriminação sofrida em função da vulnerabilidade etária, no caso das crianças pequenas. As mesmas não teriam possibilidade ainda de problematizar o que se passa, em determinada sociedade, sofrendo pela impossibilidade de expressão da diferença e multiplicidade.

É uma coisa de consumir o brinquedo, uma vez que obteve, não tem mais função. Então, acho que mudou um pouco de lugar atualmente, eu vejo isso (...). E na escola, por exemplo, onde eu trabalho (...) o excesso já aparece, o consumo aparece, a gente percebe, aparecem poucos brinquedos, e o repertório de brincadeiras bem pequeno, bem reduzido, você vê pouca fantasia nesse lugar, pouco faz de conta. (Psicóloga, 48 anos).

Hoje, o brinquedo é globalizado, porque, através da mídia, das propagandas, então os alunos querem adquirir aquilo, né? (...). É carrinho a pilha, carrinho com controle remoto. Infelizmente, a gente vê tudo isso na mídia. Mas esses brinquedos não são acessíveis à realidade de alguns, e o que a gente mais teme é no choque com esses alunos, com a comunidade, com a realidade nossa, porque, se um aluno 
ganha de presente de uma madrinha que tem uma condição melhor e traz para a sala de aula, isso já gera assim um conflito entre eles. (...). E com isso a gente vê assim o poder e o querer, aí o poder e o querer no brincar, ele fica distante de alguns e isso entristece a gente. (Pedagoga, 50 anos).

Se você for pensar nos brinquedos, hoje, o que é que eles têm? O que que eles trazem? Eles trazem uma relação muito forte com o consumismo, eles trazem uma relação com o comprar, e você deixa de lado um pouco a relação com o brincar (...). Mas é muito difícil você hoje fugir dessa situação do comprar um brinquedo, porque você está bombardeado o tempo inteiro com a mídia, então, você tem o Dia das Crianças, você tem o Natal, você tem tantas outras coisas que diz assim: "Compre", "Compre", "Compre". (Pedagoga, 42 anos).

A relação entre brinquedo, mídia e consumo foi um elemento que surgiu, durante as entrevistas. As entrevistadas demonstraram preocupação com o excesso de consumo, disseminado pela mídia, no qual o brinquedo e o brincar perderam a relação com a fantasia, assumindo uma relação comercial. Hoje, já existem movimentos, denunciando o consumismo e realizando críticas à publicidade dirigida às crianças. Em relação ao que as entrevistadas observaram, na sua experiência profissional, foram relatadas providências, tais como: o fornecimento de uma maior diversidade de brinquedos, ligados à cultura africana e às relações de gênero como tentativas de ruptura com os modos de ser cristalizados.

Até hoje as pessoas ainda falam assim: "Menino não brinca com boneca, porque boneca é de menina", mas, na minha sala de aula, as bonecas estão abertas a todos. $E$ os meninos interagem também no brincar com as meninas (...). Eles pegam as bonecas sem ter aquele machismo que era colocado entre eles. Então, a gente deixa muito natural, em eles pegarem, fazerem a cama e trazer, e ter os bonecos, porque tem o aniversário das bonecas e dos bonecos, então, os meninos cuidam dos bonecos deles e os bonecos deles estão sempre, sempre interagindo com as bonecas das meninas. (Pedagoga, 50 anos).

Eu mesma tento passar para eles a questão da cor, porque eu já percebi que as bonecas negras a gente precisa estar colocando, incluindo nas nossas atividades, porque mesmo os alunos negros é difícil alguém chegar aqui com uma boneca negra. Elas sempre são presenteadas com bonecas brancas, até mesmo porque no mercado as bonecas negras são caras, são poucas e são caras (...). Aqui na escola, desde a sua fundação que nós temos, acho que por estarmos incluídos nessa comunidade, aí a gente tem brinquedos e bonecas negras, mas no universo lá fora é difícil. (Pedagoga, 50 anos).

A gente tava trabalhando a mankala, a mankala é um jogo africano e que parte do princípio da semeadura, é um jogo matemático. Então, a mankala que é um jogo africano, na verdade, trabalhar jogos que venham de vários lugares do mundo. Então, isso ajuda a criança a perceber que a brincadeira ela tem em todo o lugar, que não é só o brinquedo dela, que tem de outras histórias e de outras culturas também. (Pedagoga, 42 anos).

É interessante perceber, a partir da fala das entrevistadas, como já existe um movimento nas escolas preocupado com a oferta às crianças de uma maior diversidade no brinquedo e no brincar, mostrando à criança que existem várias possibilidades de ser e de estar no mundo, e não apenas as limitadas pelos padrões enraizados na sociedade atual. Porém, ainda há muito a ser feito. A falta de brinquedos, os quais expressariam a diversidade de gênero, raça, etnia e geração permanece grande e o oferecimento escolar das brincadeiras no plano da fantasia e da formação de coletivos também sendo limitada face ao racismo e aos recortes de gênero (Dornelles, 2003).

\section{Racismo na escola, ontem e hoje}

Durante as entrevistas, as manifestações de racismo na escola foram relatadas em diferentes momentos. Emergiram nos relatos as narrativas de experiências vividas na escola, durante a infância.

E na escola muito comum, inclusive de professores, isso era bem comum, de professor poder se manifestar em relação a essas coisas, de chamar mesmo, de chamar de "negrinha". E com colegas tipo "não dá a mão para ela, porque ela é preta”, então eu ia brincar de roda, não podia brincar de roda, na hora que você entrava na roda se desfazia a roda. (Psicóloga, 48 anos).

Então era aquele modelo de professor branquinho, de não ter contato, era uma escola assim um nível bom, precisava fazer teste para ingressar. Eu senti a diferença, a diferença no contato, e não tínhamos isso, não tínhamos aquele contato, e eu me lembro que os outros que chegavam que eram indicados, que eram branquinhos, tinham um tratamento diferente. (Pedagoga, 50 anos).

Os relatos acima demonstram um sofrimento a que as crianças negras estão expostas e as expressões de racismo comumente sofridas. Inclusive, uma das educadoras entrevistada relatou experiências de racismo na escola vividas pela filha, provocando e atualizando o sofrimento experimentado quando criança, na escola também. Ela expôs duas situações: na primeira, ao cursar a alfabetização, a filha da entrevistada sofreu violências físicas (chutes na barriga) de um dos colegas de classe:

Porque ele não gosta de preto, de negro, e bastava ela chegar, ela sempre foi muito comunicativa, bastava ela chegar que ele já estava batendo, quer dizer, o pé era uma forma dele separar (...).(Pedagoga, 50 anos). 
Posteriormente, ela se refere a uma situação vivida durante um evento de dança, na escola, sobre a África:

A coreografia era com a música "Pérola Negra",de Daniela, e quando todo mundo esperava entrar a pérola negra, não por ser minha filha, mas que dançava muito bem, que era a única que tava fazendo escola de dança, entrou uma pérola branca (...). (Pedagoga, 50 anos).

E, por último, ao relatar as experiências de suas práticas profissionais no ambiente educacional, evidencia-se um processo de branqueamento, instalado ou em curso em muitas crianças:

Têm na prateleira bonecas negras e bonecas brancas, aí "Ai, eu quero a branca, eu quero a branca, eu quero a branca", então, eu vejo que mesmo os negros, aqui, eles não querem. Quando a gente vai falar de etnia, eles não querem ser negros, "Eu não sou negro, eu não sou preto não", eles dizem que são marrons, mas que não são pretos. Teve uma atividade que tava em um livrinho que os meninos trouxeram, de pintar (...), aí tinha assim: "Pinte na boneca a cor que for a cor dos seus olhos", e veio verde, e veio azul, veio amarelo, só não veio preto; aí eu perguntei "Qual a cor dos seus olhos?", ela repetiu que era marrom, ela sabia que não era o verde que ela pintou, que não era o azul que ela pintou, mas também ela não pintou marrom, porque ela acha que a cor escura é uma cor feia. (Pedagoga, 50 anos).

O processo de branqueamento, conforme Bento (2012), se dá pelo fato de a figura do branco ser considerado um ideal afirmado e reafirmado, permanentemente de sorte que se observa nas crianças uma negação como forma de defesa do racismo. Com efeito, não queremos afirmar políticas sectaristas, mas questioná-las em seus efeitos de produção de sofrimento, pelos preconceitos e discriminações negativas experimentadas por grupos considerados vulneráveis a esses processos sociais.

\section{Considerações Finais}

O presente artigo buscou problematizar como o analisador brinquedos e brincadeiras na escola modulou a construção da mulher negra e da mulher negra educadora. A partir das entrevistas analisadas, foi possível pensara história de vida, em especial, de escolarização, associada às relações de poder e saber, presentes na sociedade, o que colabora com a difusão de estereótipos, tanto de raça quanto de gênero. Outro ponto importante é o fato de as entrevistadas possuírem uma preocupação, na sua prática, em fornecer brinquedos que possibilitem a diversidade, porém, os processos de branqueamento e negação da negritude continuam existindo, na vida de crianças brasileiras, em variadas situações.

A categoria profissional das entrevistadas é um elemento de grande importância, no debate em pauta. A psicologia e a pedagogia são profissões que, atualmente, levantam a temática da diversidade e lutam contra a desigualdade e o preconceito. Também é válido ressaltar como a rememoração ensejada pela entrevista pôde provocar nas participantes uma atualização de experiências e práticas.

Espera-se que as contribuições deste texto colaborem para as políticas públicas de educação de crianças, ao assinalar os efeitos políticos, éticos e estéticos do acesso e da invenção de brinquedos capazes de propiciar a crítica social da produção da desigualdade, por meio da história da educação de crianças e na formação de professores, bem como no currículo.

\section{Referências}

Barros, M. L. (2012). Narração de mitologias afro-brasileiras na educação infantil: possibilidades de atuação para uma aprendizagem democrática. Rev. SPAGESP, Ribeirão Preto, v.13, n.1.

Bento, M. A. S. (2012). Branqueamento e branquitude no Brasil. Em I. Carone, \& M. A. S. Bento (Orgs.), Psicologia social do racismo. Rio de Janeiro: Vozes.

Brasil (1996). Lei 9394 de 20 de dezembro de 1996. Estabelece as Diretrizes e Bases da Educação Nacional. Brasília, DF.

Brasil. Ministério da Educação e do Desporto. Secretaria de Educação Fundamental. (1998). Referencial Curricular para a Educação Infantil - Vol. 2. Brasília: MEC/SEF.

Brougère, G. (2010). Brinquedo e cultura. São Paulo: Cortez.

Costa de Souza, Y. (2010). Espelho, espelho meu: as crianças e a questão étnico-racial. Em A. P. Brandão, \& A. L. Trindade (Orgs.), Modos de brincar: caderno de atividades, saberes e fazeres. Rio de Janeiro: Fundação Roberto Marinho.

Cruz, L. M., Silva, Z. G., \& Souza, M. L. (2012). O brinquedo e a produção do gênero na educação infantil: Uma análise pósestruturalista. Recuperado: 24 jan. 2013. Disponível: <www. periodicos.ufes.br/gepss/article/download/3880/3095 >

Cruz, M. B. (2012). Brincando com cadeirantes, idosos, negros e princesas: A diversidade por meio de brinquedos infantis. Recuperado: 26 jun. 2012. Disponível: < http:// www.cadernosdapedagogia.ufscar.br/index.php/cp/article/ viewFile/376/176 >

Deleuze, G. (1995). Crítica e clínica. São Paulo: Editora 34.

Dornelles, L. V. (2003). O brinquedo e a produção do sujeito infantil. Centro de Documentação e Informação sobre a Criança. Universidade do Minho. Instituto de Estudos da Criança. 2003. Recuperado: 26 jun. 2012. Disponível: < http://cedic.iec.uminho. pt/Textos_de_Trabalho/textos/obrinquedo.pdf $>$. 
Ferreira, R. F. (2000). Afrodescendente: Identidade em construção. Rio de Janeiro: Pallas.

Ferreira, R. F., \& Camargo, A.C. (2011). As relações cotidianas e a construção da identidade negra. Psicol. cienc. prof., Brasília, v.31, n.2. Recuperado: 11 mai. 2012. Disponível: <http://www.scielo.br/ $\mathrm{pdf} / \mathrm{pcp} / \mathrm{v} 31 \mathrm{n} 2 / \mathrm{v} 31 \mathrm{n} 2 \mathrm{a} 13 . \mathrm{pdf}>$.

Reis, M. C. G. (2010). Corporeidade e infâncias: reflexões a partir da lei $n^{\circ}$ 10.639/03. Em A.P. Brandão \& A. L. Trindade (Orgs.). Modos de brincar: caderno de atividades, saberes e fazeres. Rio de Janeiro: Fundação Roberto Marinho.

Roveri, F. T., \& Soares, C. L. (2011). Meninas! Sejam educadas por Barbie e "com" a Barbie... Educ. rev., Curitiba, n. 41. Recuperado: 7 mai 2012. Disponível: http://www.scielo.br/scielo.php?pid=S010440602011000300010\&script=sci_arttext

Santana, P. M. S. (2010). "Um abraço negro": afeto, cuidado e acolhimento na educação infantil. Em A.P. Brandão, \& A. L. Trindade (Orgs.). Modos de brincar: caderno de atividades, saberes e fazeres. Rio de Janeiro: Fundação Roberto Marinho.

Santana, P. M. S.(2006). Educação infantil. Em Ministério da Educação; Secretaria da Educação continuada, Alfabetização e Diversidade. Orientações e Ações para Educação das Relações Étnico-Raciais. Brasília: SECAD.
Souza, A. L. S., \& Croso, C. (Coord.). (2007). Igualdade das relações étnico-raciais na escola: possibilidades e desafios para a implementação da Lei 10.639/2003. São Paulo: Peirópolis: Ação Educativa, Ceafro e Ceert.

Souza, S., Lopes, T. M., \& Santos, F. G. S. (2007). Infância negra: a representação da figura do negro no início da construção de sua identidade. Em Universidade Federal do Maranhão, Programa de Pós-Graduação em Políticas Públicas (Org.), Anais da III Jornada Internacional de Políticas Públicas Questão Social e Desenvolvimento no século XXI. São Luís, MA. Recuperado: 6 mai. 2012. Disponível: http://www.joinpp.ufma.br/jornadas/ joinpplll/html/trabalhos/eixotematicod/76b6e5093718cec24873se phora\%20souza_tarc\%c3\%8dlia\%20lopes_fabianne\%20santos. pdf

Spink, M. J. (Org.). (2004). Práticas discursivas e produção de sentido no cotidiano: Aproximações téoricas e metodológicas. São Paulo: Cortez.

Torrão Filho, A. (2005). Uma questão de gênero: onde o masculino e o feminino se cruzam. Cadernos Pagu, Campinas, n. 24. Recuperado: 01 jul. 2013. Disponível: < http://www.scielo.br/pdf/ cpa/n24/n24a07.pdf >.

\section{Sobre as autoras}

Marilda Castelar (marildacastelar@bahiana.edu.br)

Psicóloga. Doutora em Psicologia Social pela PUC-SP e Professora da Escola Bahianade Medicina e Saúde Pública (EBMSP) - Salvador - BA.

Flávia Cristina Silveira Lemos (flaviacslemos@gmail.com)

Psicóloga. Doutora em História Cultural/UNESP. Professora adjunta IV em Psicologia/UFPA na Graduação e na Pós-Graduação.

Jamille Georges Reis Khouri (jamillekhouri11.2@bahiana.edu.br)

Estudante do Curso de Psicologia da EBMSP.

Thaís Andrade (thais_andrade@gmail.com)

Estudante do Curso de Psicologia da EBMSP. 